\title{
O DESENVOLVIMENTO DAS CAPACIDADES INTELECTUAIS NA RESOLUÇÃO DE PROBLEMAS NOS ANOS INICIAIS DO ENSINO FUNDAMENTAL
}

\author{
Marcia de Lima Marinho ${ }^{1}$ \\ Felipe da Costa Negrão ${ }^{2}$
}

\begin{abstract}
RESUMO
Este estudo buscou promover uma reflexão da distância existente entre a matemática ensinada na escola e matemática que o aluno precisa para o desenvolver de sua vida. Mediante o exposto, este artigo tem o objetivo de acentuar a relevância de desenvolver as capacidades intelectuais e práticas dos alunos dos anos iniciais na resolução de problemas no contexto matemático relacionado ao cotidiano. A metodologia utilizada para desenvolver essa pesquisa é de cunho bibliográfico com uma abordagem qualitativa a partir de livros e artigos, apoiada em autores clássicos e contemporâneos, que se dedicam as pesquisas no ensino de matemática e educacionais. Com isso, o resultado do trabalho apresenta o quanto é relevante o conhecimento das estratégias pedagógicas para o aprendizado do aluno, que a matemática só parece difícil se não for contextualizada com o cotidiano e a realidade social em que o discente está inserido.
\end{abstract}

Palavras-chave: Educação Matemática. Resolução de Problemas. Raciocínio Lógico.

\section{INTRODUÇÃO}

Os problemas/paradigmas que giram em torno do ensino da Matemática abriram questões no qual este artigo busca analisar, sugerindo ao professor que reavalie a concepção de como ensinar e de como se aprende matemática, ademais articular os conteúdos da disciplina com as questões sociais do cotidiano, permite uma discussão aprimorada em virtude do que o aluno já conhece e de como poderá desenvolver-se especialmente nas atividades em equipes, e a resolução de problemas proporciona um ambiente produtivo tornando o aluno ativo retirando a passividade da memorização.

A pesquisa tem como objetivo geral desenvolver as capacidades intelectuais e práticas dos alunos dos anos iniciais na resolução de problemas no contexto matemático relacionado ao cotidiano, embasando os objetivos específicos que buscam analisar as dificuldades constantes em resolver os problemas propostos, induzindo o raciocínio lógico do aluno e assim promover discussões referentes aos diferentes procedimentos utilizados para atingir os resultados.

\footnotetext{
1 e-mail: marcianiltonlins@gmail.com

2 e-mail: felipe.unl@hotmail.com
} 
A criança desde cedo tem contato mesmo que informalmente com noções matemáticas e é relevante familiarizá-la com esses conceitos, para que possa estabelecer suas primeiras impressões e elaborar suas hipóteses solucionando problemas. É necessário que o professor explore essas possibilidades conforme a natureza do problema, pois pode se melhorar a aprendizagem que se quer obter, antes passada de forma tradicional-conteudista, sem a utilização do raciocínio lógico.

O aluno necessita ser envolvido em atividades matemáticas que permitam a construção de conhecimentos, de maneira que contribua para uma aprendizagem significativa, o professor deve também compreender o aluno, suas dificuldades e suas formas de construir aprendizagens, porém precisa estar aberto para as novas metodologias de ensino, olhar e repensar como a matemática vem sendo ensinada durante anos e construir significações para com seus alunos, entendendo que todos estão em constante formação.

Atualmente o ensino passa por uma série de transformações, e para a educação matemática, novos paradigmas contribuem para amenizar ou desvincular a disciplina como sendo um grande problema da educação básica. É preciso que o ensino esteja voltado para a formação do cidadão, por isso é de suma importância que se relacione a matemática escolar com o cotidiano do aluno, para que ele questione consigo mesmo e com o outro suas habilidades para chegar a um resultado, atingindo seus objetivos e que o mesmo possa utilizar cada vez mais o que aprende na escola em sua rotina.

Sendo assim essa pesquisa tem caráter bibliográfico com uma abordagem qualitativa, com a utilização de livros e artigos, tencionando neste momento a maneira como é explicada a matemática e de como é relacionado o conteúdo científico com os problemas postos pela prática social, integrando num novo nível de desenvolvimento do educando a respeito da temática.

Este artigo divide-se em três seções: a primeira consiste nas estratégias para o docente diagnosticar dificuldades nas resoluções de problemas, a segunda evidencia aspectos relevantes no desenvolver do raciocínio lógico matemático nos alunos dos anos iniciais e a terceira expressa a importância de debater as estratégias utilizadas nos anos iniciais para uma aprendizagem significativa.

\section{ESTRATÉgIAS PARA O DIAGNÓSTICO DE DIFICULDADES NAS RESOLUÇÕES DE PROBLEMAS}


A Matemática existe desde a antiguidade, surgiu por necessidades da vida diária e desde sua origem constitui-se de inúmeras regras isoladas, dessa forma evoluiu como as demais ciências e reflete sobre sociedade como um grandioso instrumento de conhecimento e domínio público. Consequentemente o docente precisa ter a didática como uma fonte de conhecimento necessária para uma constante mudança no que tange os conceitos formados sobre a disciplina. Assim sendo, só será possível mudar este conceito se também houver mudanças no ensino, pois D’Ambrósio $(1991$, p.1) diz que: “... há algo de errado com a Matemática que estamos ensinando. O conteúdo que tentamos passar é inútil”.

Aprender Matemática é importante não apenas para se resolver situações-problemas de interesse pessoal, sendo uma competência humana essencial para que os alunos reflitam diante de situações, que em grande parte são apresentadas pelas interações sociais. A esse respeito, Panizza (2011, p.113) menciona que:

A aprendizagem matemática, como já mencionamos, baseia-se na resolução de problemas e na reflexão sobre o que foi feito: os procedimentos empregados e os conhecimentos envolvidos devem converte-se em objeto de reflexão. [...] os colegas e o professor são aqui cruciais, isto é, as explicações, as confrontações e as justificativas entre alunos são um fator de progresso para todos (PANIZZA, 2011, p.113).

Dessa forma, a matemática na educação básica é de suma importância para desenvolver competências no pensamento quantitativo na contemporaneidade, e os professores que lecionam a matéria nos anos iniciais do Ensino Fundamental tem, nesta concepção, a responsabilidade social e educativa de conhecer profundamente o material ensinado, para poder desenvolver a participação plena dos seus alunos, fazendo conexões com outras áreas do conhecimento oferecendo instrumentos que eles possam superar seus limites pessoais, criando hábitos de estudo e o gosto de aprender Matemática.

Oliveira (2015, p.67) afirma que:

Trabalhar de forma a que o aluno compreenda a Matemática implica entender seus estranhamentos na relação com a disciplina, ajudando-o a interpretar esse estranhamento e conduzindo-o num movimento de redescoberta/reconstrução dos conceitos matemáticos. $\mathrm{O}$ aluno compreenderá os conceitos matemáticos a partir das possibilidades de sentidos que encontrar nos textos, bem como poderá fazer uma leitura do mundo em que vive e também interpretá-lo matematicamente.

Deste modo, é relevante que se elabore situações problemas, e se averigúe qual é o domínio que cada criança traz consigo sobre o assunto que deseja abordar, quais serão as possibilidades e as dificuldades de cada uma para enfrentar os desafios propostos, garantindo 
formas de pensamento, criação e amadurecimento de ideias, dando exemplos que facilitem a compreensão, desenvolvendo suas potencialidades na construção de conceitos matemáticos.

A atividade deve propor um verdadeiro problema para resolver, deve permitir utilizar os conhecimentos anteriores e, ao mesmo tempo, oferecer uma resistência suficiente para levar o aluno a fazer evoluir esses conhecimentos anteriores, a questioná-los, a conhecer seus limites, a elaborar novos (CHARNAY, Apud PANIZZA, 2011, p.113).

Sendo assim, o professor deve estimular a leitura para ampliar o vocabulário, visando favorecer a assimilação de enunciados, nomenclaturas e procedimentos convencionais, desenvolvendo a lógica matemática envolvida no processo da resolução de problemas, construindo imagens positivas permitindo-lhes ver a disciplina como uma ciência viva que contribui para a compreensão e o agir sobre determinadas situações.

Eles também utilizam de representações tanto para interpretar o problema como para comunicar suas estratégias de resolução. Essas representações evoluem de formas pictóricas (desenhos com detalhes nem sempre relevantes para a situação) para representações simbólicas, aproximando-se cada vez mais das representações matemáticas (BRASIL, 2001, p.45).

Ministrar aulas de Matemática nos anos iniciais, no que se refere à resolução de problemas é saber lidar com tradições, práticas sociais, culturais e regionais dos alunos, inovando as metodologias de acordo com a necessidade e identidade da turma, trata-se de um processo de construção na contribuição para o desenvolvimento intelectual dos mesmos.

Silveira (2015, p. 131) relata que "o aluno, ao resolver um problema, segue regras e sabe que o resultado já está previsto pelo professor. Ele decide o caminho a seguir para encontrar a solução, numa liberdade limitada, porque existe motivo na decisão”. Portanto, há uma necessidade por parte do docente de organizar, planejar e estruturar previamente atividades adaptadas para a classe, oferecendo-lhes condições de refletir e encontrar meios para chegar ao resultado esperado, quebrando paradigmas e mostrando que matemática é acessível para todos.

Compartilhar de um mesmo repertório, sem confundir o discente, criar aulas mais atrativas com metodologias desafiadoras, decorre da linguagem utilizada, de maneira que o aluno compreenda e interprete essa linguagem redescobrindo e reconstruindo seus conceitos matemáticos. Ademais, para eles enfrentem situações-problema em múltiplos contextos, incluindo as situações imaginadas, não diretamente relacionadas com o aspecto prático- 
utilitário, possibilita expressão nas respostas e sintetização nas conclusões com diferentes registros e linguagens (BRASIL, 2017, p.265).

Refletir sobre a importância da linguagem matemática utilizada, ajuda na compreensão do que o aluno pensa e do que ele faz, pois, as linguagens nos permitem fazer trocas de sentidos e deste modo o professor ter acesso ao que aluno está imaginando. Entretanto, se essa linguagem for escassa o aluno não compreende e na maioria das vezes recorre ao colega de classe, quebrando a possível construção entre professor e aluno. Então se pode afirmar que o professor tem um papel importante, uma vez que o desenvolvimento do aluno requer que o docente oportunize um ambiente estimulador e teça vínculos positivos com a matemática.

A formalização da linguagem matemática, estruturada na lógica dedutiva, impossibilita outras interpretações, pois ela quer operar com as supostas evidências de um sentido único, com uma linguagem ideal evite se confrontar com as ambiguidades da linguagem natural. Nesse sentido, o papel do diálogo entre professor e aluno busca do sentido de conceitos matemáticos estabelece um processo de compreensão. As possibilidades de compreender colocam professor e aluno em acordo (SILVEIRA, 2015, p.108).

Nesse sentido, o professor não ensina conceitos aos alunos, e sim ajuda a construí-los, a organizar seus pensamentos e analisar criticamente a problemática. Portanto, ensinar matemática não se limita ao fazer contas ou resolver problemas, vai além de decodificar linguagens, analisar situações reais ou imaginárias, fazer estimativas estimulando o raciocínio lógico na busca de entender os princípios, criar meios para se chegar a um fim.

\section{ASPECTOS RELEVANTES NO DESENVOLVIMENTO DO RACIOCÍNIO LÓGICO MATEMÁTICO NOS ALUNOS DOS ANOS INICIAIS}

As metodologias de ensino estão passando por inúmeras transformações, pois o que é ensinado na escola deve despertar nos alunos capacidades e novos meios de solucionar problemas, compreender fatos, organizar e planejar, sendo assim para que isso ocorra, induzir o raciocínio lógico do educando seria um método eficaz para motivá-lo para o estudo matemático, evidenciando fortemente na formação de capacidades intelectuais, na estruturação do pensamento e na agilização do raciocínio dedutivo do aluno.

Para tanto, é importante que a Matemática desempenhe um papel decisivo na vida da criança com conhecimentos que favoreçam o desenvolvimento do seu raciocínio, fazendo 
tentativas à sua maneira, construindo uma lógica própria. “A Matemática comporta um amplo campo de relações, regularidades e coerências que despertam a curiosidade e instigam a capacidade de generalizar, projetar, prever e abstrair, favorecendo a estruturação do pensamento e o desenvolvimento do raciocínio lógico" (BRASIL, 2001, p.24).

Assim o aluno em sua memória reconstrói o conceito matemático partindo do que lhe é passado, projetando novos sentidos, buscando novas soluções para os problemas, reinterpretando um conceito que em determinado momento ele mesmo possa modificá-lo. Portanto, esses momentos de aprendizagem, em que o aluno se encontra sozinho, possibilitam construções de conhecimentos significativos tornando-o capaz de planejar e replanejar suas estratégias. O conceito deve ser considerado antes e depois da interpretação do aluno. O aluno descobre as propriedades do objeto e constrói o seu conceito, como um processo de reorganização e reconstrução por atos intencionais (SILVEIRA, Apud SILVEIRA, 2015, p.161).

É importante que o aluno perceba que esses métodos favorecem o desenvolvimento do seu raciocínio, que a seleção e a organização contribuem para o desenvolvimento intelectual e que os conteúdos não devem ter um único critério, uma única regra a ser aplicada. As novas formas de ensino exigem muito do profissional da educação, o que é ensinado na escola deve despertar interesse na participação ativa do aluno e toda sua experiência deve ser aproveitada.

Assim, criar um ambiente de motivação e envolvimento leva o discente a analisar o problema no seu aspecto geral, objetivando resolver o que estiver à seu alcance e o docente possibilita dessa maneira um caráter aproximativo do estudante consigo e com a matemática, criando um elo entre os conteúdos e o que o aluno vem assimilando dia após dia.

Segundo os PCNs, é importante:

[...] desenvolver capacidades intelectuais, na construção do pensamento, na agilização do raciocínio dedutivo do aluno, na sua aplicação a problemas, situações da vida cotidiana e atividades do mundo do trabalho. Além de apoiar a construção de conhecimentos em outras áreas curriculares (BRASIL, 2001, p.29).

Nesse sentido, a matemática deve ser vista pelos alunos como um conhecimento que desenvolve o próprio raciocínio, sua autonomia, seu pensamento reflexivo, sua criticidade, sua capacidade de argumentar diante de situações que geram dúvidas para a turma, trocando ideias com o professor, expondo opiniões e propondo novos caminhos para solucionar os problemas propostos em sala de aula. 
Portanto, a BNCC orienta-se pelo pressuposto de que a aprendizagem em Matemática está intrinsecamente relacionada à compreensão, ou seja, à apreensão de significados dos objetos matemáticos, sem deixar de lado suas aplicações. Os significados desses objetos resultam das conexões que os alunos estabelecem entre eles e os demais componentes, entre eles e seu cotidiano e entre os diferentes temas matemáticos (BRASIL, 2017, p. 274).

A matemática é uma disciplina que relaciona experiências, que instiga a interpretação subjetiva do aluno, que de fato também o conduz a cometer erros que construiu com seus próprios conceitos lógicos, pois não existe erro sem uma lógica “esses erros são organizados e dotados de uma lógica própria, nós não podemos dizer que seja uma negligência do aluno, e sim que sua interpretação não coincide com o conceito apresentado pelo professor" (SILVEIRA, 2015, p.141).

No entanto, as resoluções erradas, também devem ser contextualizadas como objeto de estudo na busca de respostas certas, os alunos são induzidos a argumentar suas hipóteses e interpretações durante o procedimento, tratando de encontrar semelhanças e diferenças, e o professor deve abrir, guiar e sustentar esses momentos como um campo de relações que estruturam o pensamento e o raciocínio, ficando atento a cada etapa do desenvolvimento do aluno.

Sobre isto, Piaget (1976) dizia: "Um erro corrigido [pela mesma criança] pode ser mais fecundo do que um êxito imediato, porque a comparação de uma hipótese falsa e suas consequências proporciona novos conhecimentos e a comparação entre dois erros dá novas ideias" (PANIZZA, 2011, p.139).

É possível resolver situações a qualquer área de estudo aplicando o raciocínio lógico, basta que argumentos sejam empregados e contextualizados, em especial na disciplina de matemática que possui alguns contextos, que permitem uma discussão na medida em que não encontram uma justificativa que os convençam da necessidade e da importância da disciplina em suas vidas.

A contextualização não pode ser feita de maneira ingênua, visto que ela será fundamental para as aprendizagens a serem realizadas - o professor precisa antecipar os conteúdos que são objetos de aprendizagem. Em outras palavras, a contextualização aparece não como uma forma de "ilustrar" o enunciado de um problema, mas como uma maneira de dar sentido ao conhecimento matemático na escola. (BRASIL, 2006, p. 83).

Nesse caso o contexto ensinado em sala deve ser relacionado com os problemas advindos do cotidiano, com práticas pedagógicas bem elaboradas, que promovam troca de experiências, traçando caminhos eficazes no processo de ensino aprendizagem da matemática. 
Carraher (1995) diz que "quando uma criança resolve um problema com números na rua, usando seus próprios métodos, está diante de um fenômeno matemático, devido ao conteúdo do problema [...] porque a criança certamente raciocinou".

Ademais, é relevante que se ofereça uma visão da matemática como uma ciência viva, ancorada no mundo e em interação com outros campos científicos, deixando no passado o ensino tradicional onde a matemática era vista como uma ciência isolada. Pois, "desenvolver o raciocínio lógico, o espírito de investigação e a capacidade de produzir argumentos convincentes, recorrendo aos conhecimentos matemáticos para compreender e atuar no mundo" (BRASIL, 2017, p.265), é indispensável para a compreensão das características da matemática atual, com escolhas coerentes e realistas, levando em conta suas possíveis implicações para o ensino.

\section{A IMPORTÂNCIA DE DEBATER AS ESTRATÉGIAS MATEMÁTICAS UTILIZADAS NOS ANOS INICIAIS PARA UMA APRENDIZAGEM SIGNIFICATIVA}

O ensino da Matemática não pode ser interpretado apenas com a finalidade de calcular, naturalmente também desenvolve habilidades comunicativas de representar, falar, escutar, criar, expor seus pontos de vista, explicar suas estratégias, confrontar e argumentar. Consequentemente as noções matemáticas vão sendo construídas a partir de experiências proporcionadas pelas interações com o meio, e com outras pessoas que tenham o mesmo interesse e necessidades para serem compartilhadas.

Tal educação deve permitir que se viva a experiência matemática, ao mesmo tempo como uma experiência individual e como uma experiência coletiva, e que se perceba o que é possível compartilhar, o debate com os outros. Ela deve saber estimular, por meio de desafios, cultivando os valores da solidariedade (UNESCO, 2016, p. 11).

Percebe-se que dessa forma os alunos poderão tomar decisões, agindo com propriedade de conhecimento e não apenas como executores de instruções, bem como contribuir para a formação de cidadãos autônomos, capazes de pensar por conta própria, possibilitando uma educação que forme sujeitos socioculturais, para a busca de caminhos de transformação social. Apesar de algum tempo se reconhecer a importância da interação entre os alunos e professores, e no que tange o ensino da matemática a situação de juntos buscarem por resultados facilita que professor e aluno alcancemos objetivos almejados. 
Tal situação reflete na aprendizagem do aluno que acaba expondo suas convicções, explicitando seu ponto de vista sobre o problema, utilizando de argumentos para explicar o procedimento realizado, que por sua vez faz com que eles utilizem de uma linguagem matemática compreensível, levando-o a refletir sobre os conhecimentos explicitados e seus conhecimentos individuais. No entanto, observa-se que é relevante a utilização da linguagem matemática, pois, é por meio da língua que o sujeito ressignifica sentidos alheios, entretanto, dando sentido aos seus, mas acrescenta ao interpretar e dá novos sentidos ao que lhe apresentam pré-construído.

Todo conhecimento novo construído apoiando-se sobre conhecimentos anteriores que, ao mesmo tempo, são modificados. $\mathrm{Na}$ interação desenvolvida por um aluno em uma situação de ensino, ele utiliza seus conhecimentos anteriores, submete-se à revisão, modifica-os, rejeita-os ou os completa, redefinindo-os, descobre novos contextos de utilização e dessa maneira, constrói novas concepções (PANIZZA, 2011, p.49).

Estas ideias novas interagem com as ideias relevantes ancoradas e o produto desta interação torna-se para o aprendiz, o significado das ideias acabadas de produzir (DAVID AUSUBEL, 2000), que permite tomar consciência que não há apenas um caminho a seguir, dessa maneira, a aprendizagem se torna significativa despertando a autonomia. Por isso, a matemática precisa estar ao alcance de todos, e o debate aparece como uma forma de democratização do seu ensino, isto é, a discussão precisa ser vista como meta prioritária do trabalho docente, auxiliando no desenvolvimento dessa autonomia, para que cada aluno possa confiar em seu próprio conhecimento, deixando de olhar para as coisas prontas e definidas, constituindo indícios de competências e como tal devem ser considerados.

Portanto Paulo Freire (1996, p.64) descreve em seu livro Pedagogia da Autonomia que:

Ao pensar sobre o dever que tenho, como professor, de respeitar a dignidade do educando, sua autonomia, sua identidade em progresso, devo pensar também, como já salientei, em como ter uma prática educativa em que aquele respeito, que sei dever ter ao educando, se realize em lugar de ser negado.

Assim sendo, torna-se fundamental criar um ambiente propício para compartilhamentos e exposição de ideias e saberes, onde o professor como mediador deve dar voz ao aluno deixando de ser o único ser ativo no ensino, a aprendizagem passa a ter via de mão dupla, e nesse viés os alunos passam a fazer parte do processo de ensino e aprendizagem. Ressalta Paulo Freire (1996, p.26), "que nas condições de verdadeira aprendizagem os 
educandos vão se transformando em sujeitos reais da construção e da reconstrução do saber ensinado, ao lado do educador".

Dessa forma, os processos de pensamento serão valorizados, tornando os alunos em seres ativos capazes de discutir problemáticas e sentir-se-ão contribuintes em sua formação, construindo uma nova história para a matemática, compreendendo e transformando o mundo a sua volta. Assim, o ambiente escolar possibilita relacionar atividades reais e concretas facilitando a construção do conhecimento em relação ao mundo de forma motivadora e significativa.

A matemática nunca deve ser apresentada aos alunos como verdade absoluta ou como um produto acabado, precisa ser integrada ao contexto do alunado e sua relevância para a sociedade, com finalidade de tornar-se mais humanizada. Nesse aspecto os alunos devem ser pró ativos no processo de ensinar e aprender Matemática (FREUDENTHAL, 1979, Apud SANTOS, 2017, p.69).

Consequentemente no diálogo o aluno aprende, estima e raciocina, compreende a sua lógica e o professor aprende ensinando e compreende a lógica de seu aluno. Propor que uma turma discuta sobre determinado assunto não é novidade na educação, porém na disciplina de matemática essa didática é pouco utilizada, pelo fato ser vista como uma disciplina difícil e para poucos. No entanto, isso é uma mudança a ser pensada e transformar momentos particulares onde se discutia conteúdos específicos e difíceis, em momentos prazerosos e aberto a todos.

Fica claro que nas competências específicas de matemática para o ensino fundamental, interagir com seus pares coletivamente coopera para desenvolvimento de pesquisas e descobrimento de respostas à questionamentos, buscando soluções para problemas partindo da discussão, pois é um modo eficaz de aprender em grupos, sempre respeitando o modo de pensar de todos envolvidos (BRASIL, 2017, p.265). Desse ponto de vista, pode-se almejar expectativas de aprendizagens, pois os discentes serão capazes de se posicionar diante de situações novas, e não apenas serem capazes de reproduzir os procedimentos relativamente estáveis, naturalmente, a matemática fica mais próximo possível da realidade e da necessidade desses alunos.

Consequentemente o ato de discutir ideias, cria um elo entre os alunos e professores, permite que o educando se aproxime progressivamente do objeto a ser estudado, aprende a respeitar o trabalho próprio e o dos outros, constrói coletivamente, sente-se parte do processo da sua aprendizagem, revendo sua posição como um ser ativo/produtivo e capaz. A 
matemática antes temida passa a fazer parte do seu contexto social, pois o aluno passa a compreender o quanto ela é fundamental e o quanto ela é significativa em sua realidade.

\section{CONSIDERAÇÕES FINAIS}

A realização desta pesquisa teve como pressuposto apontar algumas considerações em relação aos paradigmas em torno da disciplina de matemática. Pois o trabalho desenvolvido consistiu em esclarecer que o desenvolvimento das capacidades intelectuais na resolução de problemas nos anos iniciais do ensino fundamental é de suma importância para que o aluno em sala de aula compreenda a disciplina, porém se o professor apresentar diferentes métodos para que eles desenvolvam essas capacidades quebrará esse paradigma.

De fato, torna-se relevante analisar as dificuldades constantes nos alunos em resolver problemas propostos, pois ficou claro que os mesmos precisam compreender os conceitos para desenvolver atitudes, como por exemplo, a confiança em relação a sua própria capacidade, visto que o fazer pedagógico do professor é um instrumento essencial, portanto como mediador tem o papel de instigar o aluno a raciocinar, refletindo que a matemática faz parte do cotidiano e está sempre presente em seu contexto sociocultural.

Assim, para que isso aconteça o docente precisa induzir o raciocínio lógico do aluno na resolução de problemas, para que a cada problema resolvido o discente seja capaz de contextualizar os caminhos que ele tomou para chegar ao resultado, construindo de maneira lógica aplicações que ele mesmo possa reconstruir, desmistificando que a matemática é absoluta e que tem somente um método para a resposta correta. Logo, que a disciplina era posta como um conhecimento pronto e acabado, isso somará positivamente na construção de um cidadão consciente que sabe fazer relações dos conceitos matemáticos com a realidade que está inserido.

Em síntese, é indiscutível que o docente promova discussões referentes aos diferentes procedimentos utilizados para atingir os resultados e compartilhar ideias faz com que o ensino e o aprendizado dêem frutos promissores, pois é inerente do ser humano gostar de se sentir útil. Sendo assim, o ensino matemático passa a ser contextualizado e o trabalho em conjunto contribui na compreensão de métodos que devem ser respondidos através de uma lógica própria.

Posto isto, a Matemática passa a ser discutida de maneira realista, coerente e atrativa, passando a ser planejada e utilizada em outras disciplinas mesmo que inconscientemente. 
Através de argumentos procura-se desvincular a matéria como implicação para a formação do discente em seu período escolar e levar em conta sua funcionalidade em qualquer contexto social, pois esse estudo mostrou que o aprendizado se torna significativo se for valorizado a participação do aluno para a construção do seu aprendizado.

De fato, percebeu-se o quanto a Matemática possibilita a interação entre professores e alunos, que partindo de discussões constroem inúmeras possibilidades de resolver problemas, mesmo que seguindo por diferentes caminhos, conseguem atingir o mesmo objetivo, ou seja, a resposta esperada. Sendo assim, é preciso mostrar que aprender matemática torna-se necessário, e que sua aplicabilidade pode ser posta dentro e fora da sala de aula, passando a ser vista como uma disciplina extraescolar.

\section{REFERÊNCIAS}

AUSUBEL, D. P..Aquisição e Retenção de Conhecimentos: Uma Perspectiva Cognitiva. Tradução: Lígia Teopisto. Lisboa: Paralelo, 2000.

BRASIL. Ministério da Educação, Secretaria da Educação Básica. Orientações Curriculares Nacionais. Brasília, v. 2, 2006.

Ministério da Educação. Governo Federal. Base Nacional Comum Curricular. Parceria com Conselho Nacional de Secretários da Educação - CONSED. União Nacional dos Dirigentes Municipais da Educação - UNDME. 2017.

- Secretaria de Educação Fundamental. Parâmetros Curriculares Nacionais: matemática/ Secretaria de Educação Fundamental. - Brasília: MEC/SEF, 2001.

CARRAHER, T.; CARRAHER, D.; SCHLIEMANN, A. Na vida dez, Na escola zero. São Paulo: Cartiz, 1995.

D’AMBRÓSIO, U. Matemática, ensino e educação: uma proposta global. Temas \& Debates. São Paulo, v.4, n.3, p. 1- 15, 1991.

FREIRE, P. Pedagogia da Autonomia: saberes necessários à prática educativa. São Paulo: Paz e Terra, 1996.

MARCONI, M. A.; LAKATOS, E. M. Metodologia do trabalho científico: procedimentos básicos, pesquisa bibliográfica, projeto e relatório publicações e trabalhos científicos. 7 . ed. - 6. reimpr. São Paulo: Atlas: 2011.

PANIZZA, M. Ensinar matemática na educação infantil e nas séries iniciais: analise e propostas / Mabel Panizza; tradução Antonio Feltrin. Porto Alegre: Artmed, 2011.

PRODANOV, C. C.; FREITAS, E. C. Metodologia do Trabalho Científico: Métodos e Técnicas da Pesquisa e do Trabalho Acadêmico. - 2. ed - Novo Hamburgo: Feevale, 2013. 
RIBEIRO, S. M. B. Raciocínio Lógico. 09/2014. Disponível em:<http://www.trabalhosfeitos.com/ensaios/raciocínio - lógico/59544099> Acesso em 09 de mar de 2018.

SANTOS, A. O.; OLIVEIRA, G. S. Educação Matemática: Sentidos e Significados nas Séries Iniciais do Ensino Fundamental. 2017. Disponível em: <www.fucamp.edu.br/editora/index.php/cadernos/article/download/1036/787> Acesso em 09 de mar de 2018.

SEVERINO, A. J. Metodologia do Trabalho Científico. São Paulo: Cortez, 2007.

SILVEIRA, M. R. A. Matemática, discurso e linguagens. Contribuições para e Educação Matemática. Editora Livraria da Física, $1^{\circ}$ ed. São Paulo: 2015.

UNESCO. Os desafios do ensino de matemática na educação básica. Brasília: São Carlos: EdUFCar, 2016.

VINÍCIO, M. S. Ensino de Matemática na escola de nove anos: dúvidas, dívidas e desafios - Coleção Ideias em Ação. Anna Maria Pessoa de Carvalho (coordenadora da Coleção). São Paulo. Trilha, 2015. 